\title{
How Does Citizen Science "Do" Governance? Reflections from the DITOs Project
}

\author{
Claudia Göbel, Christian Nold ${ }^{\dagger}$, Aleksandra Berditchevskaia ${ }^{\ddagger}$ and Mordechai Haklay ${ }^{\dagger}$
}

Citizen science (CS) is increasingly becoming a focal point for public policy to provide data for decisionmaking and to widen access to science. Yet beyond these two understandings, CS engages with political processes in a number of other ways. To develop a more nuanced understanding of governance in relation to CS, this paper brings together theoretical analysis by social science researchers and reflections from CS practice. It draws on concepts from Science and Technology Studies and political sciences as well as examples from the "Doing-It-Together Science" (DITOs) project. The paper develops a heuristic of how CS feeds into, is affected by, forms part of, and exercises governance. These four governance modes are (1) Source of information for policy-making, (2) object of research policy, (3) policy instrument, and (4) socio-technical governance. Our analysis suggests that these four dimensions represent different conceptions of how science and technology governance takes place that have not yet been articulated in the CS literature. By reflecting on the DITOs project, the paper shows how this heuristic can enrich CS. Benefits include project organisers better communicating their work and impacts. In its conclusion, the paper argues that focusing on the complexity of governance relations opens up new ways of doing CS regarding engagement methodologies and evaluation. The paper recommends foregrounding the broad range of governance impacts of CS and reflecting on them in cooperation between researchers and practitioners.

Keywords: Citizen science; public engagement; public policy; governance; policy engagement

\begin{abstract}
Introduction
Citizen Science (CS) is intertwined with public policy in multiple ways, and the question of how CS can be a resource for decision-making is increasingly debated among those who organise projects as well as among politicians. Around the world, CS is considered relevant at various levels of governance from multilateral programmes, such as the United Nations Environment Programme, to supra-national institutions (the European Union) and individual member states exploring the value of CS for environmental reporting, education, and decision-making (POST 2014; Science Communication Unit 2013). Environmental protection agencies are recognising CS by issuing recommendations, cost-benefit analyses, and decision support for when to use CS to support implementation of regulatory environmental policy (NACEPT 2016; Pocock et al. 2014; Vohland et al. 2016). Increasing openness towards CS is also spreading beyond environmental and biodiversity monitoring to include health and food security, disaster response, and research policy (Schade et al. 2017). Policy publications that men-
\end{abstract}

\footnotetext{
* Institute for Higher Education Research (HoF) at University Halle-Wittenberg, DE

+ University College London, UK

₹ NESTA, UK

Corresponding author: Claudia Göbel (claudia.goebel@mfn.berlin)
}

tion CS typically highlight its potential for multiple fields and implementations (McElfish, Pendergrass, and Fox 2016) as well as data management (Schade and Tsinaraki 2016). State-sponsored capacity building projects or consultations to develop national strategies for CS have been run in Germany (Bonn et al. 2016), France (Houllier and Merilhou-Goudard 2016), and Spain (Fundacion Ibercivis 2017). Finally, the CS practitioner community is starting to connect with decision makers to demonstrate the validity and benefits of CS (Hecker et al. 2018).

Existing studies focus on how CS supports policy development, barriers, and regulatory support (e.g., Chapman and Hodges 2016). Haklay (2015) points out that policy dimensions of CS arise from geography, policy application area, and type of engagement. Existing empirical studies analyse CS projects along dimensions such as standards (Ottinger 2010), place (Newman et al. 2017), participation of stakeholders (Gobel, Martin, and Ramirez-Andreotta 2017), and data practices (Gabrys, Pritchard, and Barratt 2016). The literature typically identifies two roles for CS in policy contexts: As a data source for the development, implementation, or monitoring of regulation and as one of the targets for science policy. This idea rests on a set of basic assumptions: Politicians and formal political institutions are considered as central actors. "Science" and "politics" are understood as separate spheres, and policymaking is seen as a linear process where policy makers determine rules that CS feeds into. 
However, theoretically inspired reflections on the relationship between CS and governance structures are still rare. We argue that CS relates to political processes in ways other than as a source of data or an object of research policy. Such alternatives remain invisible in the literature at present. This paper sets out to broaden the perspective by drawing on concepts from political science as well as Science and Technology Studies (STS), an interdisciplinary research field in the social sciences and humanities which aims at better understanding science and technology as part of society. We analyse a case study taken from the pan-European project "Doing-It-Together Science" (DITOs) (http://togetherscience.eu/), including activities explicitly aimed at "policy engagement," such as multi-stakeholder roundtable discussions (Figure 1) and neglected sites of governance such as prototyping workshops. Based on these experiences, the paper presents a heuristic of relations between $\mathrm{CS}$ and governance and illustrates how the heuristic can enrich CS practice using examples from the DITOs project. Finally, the paper points out that recognising this complexity of governance relations presents alternative ways of practicing CS.

\section{Case Study of the DITOs Project}

This paper is a reflective essay that uses the case study of the EU-funded DITOs project, in which all four authors were involved. DITOs aimed to increase participation in CS across Europe by coordinating and supporting 500 public events encompassing the spectrum from top-down projects (in which members of the public join activities organised and determined by academic institutions) to bottom-up activities (in which members of the public are more actively involved in design or coordination of research focused on a problem of direct concern to them). Over the course of three years, DITOs engaged more than 1.5 million participants. In parallel to the public-facing events, the DITOs partners also ran activities with the explicit purpose of "policy engagement," i.e., reaching out to decision makers with the aims to provide information and good practice on CS and DIY science, stimulate encounters, and develop institutions, namely the European Citizen Science Association (ECSA) (Göbel and Agnello 2019). Activity formats of this policy engagement work included stakeholder roundtables, policy briefs, and international research missions ("Discovery Trips") that involved taking politicians on organised tours (Berditchevskaia, Regalado, and van Duin 2017). DITOs was one of the first large-scale CS projects funded by an EU scheme focused on public engagement with science and technology (rather than technical or basic research funding programmes). As the first capacity building project to significantly support and strengthen CS communities across Europe, DITOs is a uniquely relevant and multifaceted case study for the relationship between CS and governance processes.

This paper uses empirical observations from the DITOs project to articulate a broader argument about the relationship between CS and governance processes. It uses a mixture of social science methods including autoethnography (Ellis, Adams, and Bochner 2011) to reflect on stakeholder roundtables, textual analysis (Nimmo 2011) to examine the policy framing of DITOs, and ethnographic observations of devices (Law and Ruppert 2013) when reporting on workshops. Based on these observations and vignettes from the DITOs activities, we outline four governance modes of how CS and governance relate. Taken together, these four modes constitute a heuristic of

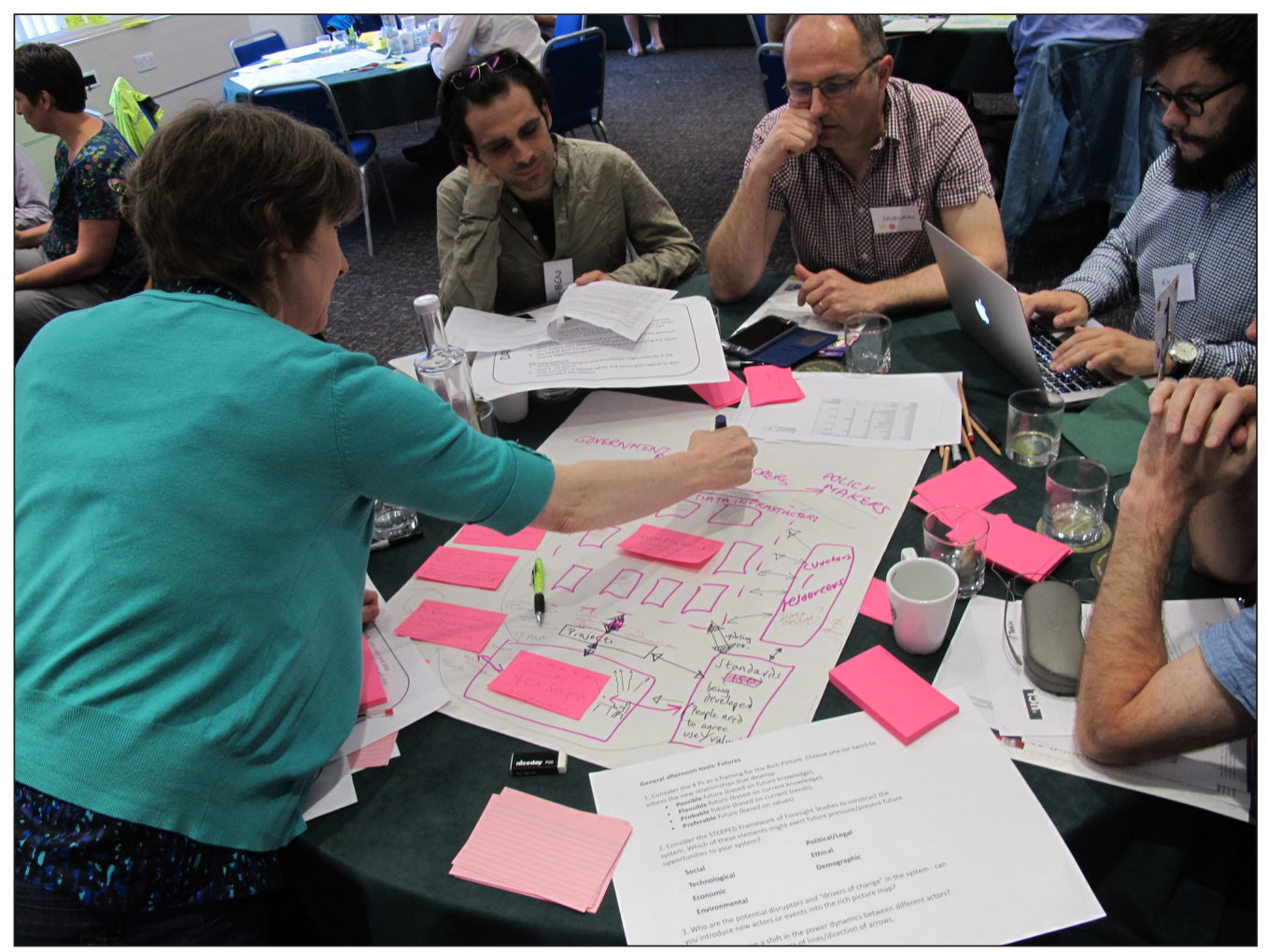

Figure 1: DITOs European stakeholder roundtable on environmental citizen science, May 2018, London. Photo: Alexandra Berditchevskaia. 
how CS feeds into, is affected by, forms part of, and exercises governance. We argue that these categories are relevant beyond the DITOs project and that they represent archetypal relationships of CS. The primary aim of our analysis is to share experiences and to stimulate deeper discussions amongst CS practitioners and social scientists. We recognise that there may be additional modes to be mapped, and we invite others to test the four that we have described and elaborate upon them further.

\section{Citizen Science and Governance}

CS is increasingly becoming a focal point for public policy to provide data for decision-making and to widen access to the process of science. Yet beyond these two understandings, CS can engage with "the political" in a number of other ways. We propose to refine the terminology used to address such relationships. We argue that the term "governance" can function as a useful tool to speak and think about political dimensions of CS and to surface dimensions that usually remain invisible. We will do this first by drawing on concepts from STS and political sciences to provide an enriched definition of "policy" as "governance." Second, we will use examples from the DITOs project to propose different modes of how CS and governance can be related to each other. We also will discuss how our heuristic relates to what is usually called CS governance models.

In political sciences, the term governance has been defined as "institutionalized modes of social coordination to produce and implement collectively binding rules (e.g., policies), or to provide collective goods" (Börzel and Risse 2010: 114). The term was introduced to enlarge the view of the process of policy-making beyond formal political institutions by capturing non-hierarchical modes of coordination, for instance through networks or markets, as well as roles of non-state actors in public policy-making and implementation. STS broadened the idea of "governance" to describe an expanded network of influential actors and organisations that drive the development and uptake of science and technology through society. For example, Jasanoff (2005) has highlighted the intertwined nature of science (and technology) and politics by examining how concepts in the theory of democracy are informed by ideas of science, how the latter are incorporated into projects of nation-building, or how political culture is linked to what is considered public knowledge.

Based on this literature, we use an enriched concept of governance. In addition to formal political institutions it also considers non-state actors such as technologies and standards to have governance implications. It uses the notion that science and politics are mutually dependent and shaping each other. Governance is not a linear top-down process but rather a multidirectional one. The implications of such approaches are that governance can be understood to take place inside as well as outside of recognisable political institutions, such as parliaments, and to involve a much broader group of people and entities such as technologies and standards. In such a view, the spheres of science and politics are brought closer conceptually to become mutually determining and interlinked. This allows us to consider spaces, settings, and relations of governance beyond political programmes and ethical rules and to take into account mutual relations. Finally, inspired by Latour (2007), who treats different understandings of "the political" as different moments in the trajectory of a public issue, we use governance as an overarching and flexible concept encompassing a spectrum of possible meanings and thus relations with CS.

In CS practitioner communities, the term "governance" is associated with so-called "governance models" of CS projects. Although not explicitly used in the scientific literature, the phrase "citizen science governance models" has become a shorthand for the five-part model of Public Participation in Scientific Research distinguishing "contractual, contributory, collaborative, co-created, and collegial" projects. This five-part model from Shirk et al. (2012) focuses on power relations within CS projects, such as the way that volunteers interact with scientists and volunteers' relations to project outcomes. In contrast, our framing of governance focuses on CS projects as part of a wider ecosystem of science policy, funding processes, and direct transformations of the world, as well as decision-making. Hence the classification from Shirk et al. as well as others that similarly deal with CS governance models within projects (Haklay 2013; Wiggins and Crowston 2011) have a different focus than the heuristic proposed in this paper.

The present paper develops a heuristic of how CS feeds into, is affected by, forms part of, and exercises governance. We present four governance modes that we identified in DITOs: CS as (1) source of information for policy-making, (2) object of research policy, (3) policy instrument, and (4) socio-technical governance (Table 1). Each of the modes is illustrated with a vignette that includes a basic description of the governance mode, relations to other project examples and literature, an illustrative example from DITOs activities, and a brief reflection.

\section{Governance Modes \\ Citizen science as a source of information for policy-making}

We start with the governance mode that is concerned with the mobilisation of information for policy-making. This mode has already been widely recognised and elaborated within the literature on CS (e.g., Bonney et al. 2014; Schade et al. 2017). It describes the use of outputs from CS, such as data and knowledge, as inputs for the implementation and monitoring of regulation. While this mode is discussed for a wide range of applications, it has been most thoroughly elaborated for environmental policy (Haklay 2015). Because it has already been vastly covered, we limit our discussion and example of this mode to the most essential points.

The most simplified instantiation of this mode posits citizens as data collectors whose contributions to environmental monitoring are shepherded by public authorities. This idea is closely related to the concept of crowdsourcing (Howe 2006). Many publications also advocate for an expanded role for citizens beyond gathering data, e.g., more stages of the policy cycle, such as agenda setting and review of policies, shall become open to contributions from CS (NACEPT 2016; Schade et al. 2017). A 2018 survey of European CS projects that analysed the role of CS in environmental policy-making (Bio Innovation Service 2018) 
Table 1: Summary of relationships between CS and governance from the DITOs project.

\begin{tabular}{|c|c|c|c|}
\hline $\begin{array}{l}\text { Governance } \\
\text { mode }\end{array}$ & $\begin{array}{l}\text { Role of CS in different relations } \\
\text { of governance }\end{array}$ & $\begin{array}{l}\text { Key elements/ } \\
\text { components }\end{array}$ & Example from DITOs \\
\hline $\begin{array}{l}\text { Information for } \\
\text { policy-making }\end{array}$ & $\begin{array}{l}\text { CS as a source of information to feed into } \\
\text { science and thus lead to policy improvement }\end{array}$ & $\begin{array}{l}\text { - Data } \\
\text { - Knowledge } \\
\text { - Standards }\end{array}$ & Stakeholder roundtable \\
\hline $\begin{array}{l}\text { Object of } \\
\text { research policy }\end{array}$ & $\begin{array}{l}\text { CS as an approach of doing research and } \\
\text { science communication that is regulated by } \\
\text { public authorities }\end{array}$ & $\begin{array}{l}\text { - Stakeholders } \\
\text { - Policy makers } \\
\text { - Policy events }\end{array}$ & Stakeholder roundtable \\
\hline Policy instrument & $\begin{array}{l}\text { CS being used as an instrument to advance } \\
\text { political agendas on science and society }\end{array}$ & $\begin{array}{l}\text { - Political agendas } \\
\text { - Funding calls } \\
\text { - Proposals }\end{array}$ & DITOs project as a whole \\
\hline $\begin{array}{l}\text { Socio-technical } \\
\text { governance }\end{array}$ & $\begin{array}{l}\text { CS as direct governance via non-policy actors, } \\
\text { e.g., the public, stakeholders, technologies }\end{array}$ & $\begin{array}{l}\text { - Public problems } \\
\text { - Prototypes } \\
\text { - Participants }\end{array}$ & Prototyping workshops \\
\hline
\end{tabular}

demonstrated that CS also can make a valuable contribution towards realising the United Nations Sustainable Development Goals (https://sustainabledevelopment. un.org), an international policy agenda stipulating global aims and action plans for international development and sustainability. In addition, there are bottom-up CS projects born out of activism in the face of environmental degradation and disasters. Often, they aim at civic mobilisation to call for action by public authorities on issues of environmental health and justice. An example is activities of the Public Laboratory for Open Technology and Science that include various techniques for civic mapping and water quality monitoring (Rey-Mazón et al. 2018). Such CS activities provide communities with an independent capacity to generate and use environmental data (Gabrys, Pritchard, and Barratt 2016).

Experiences of this mode within the DITOs project were mainly indirect, e.g., consolidating ties between national CS networks and policy makers for environmental sciences (Göbel and Agnello 2019) and field building efforts, e.g., establishing a European network of Bioblitz organisers (DITOs 2017a). One concrete example is the European stakeholder roundtable on environmental CS held in May 2018 in London. The focus of this one-day event was the implementation of CS in the area of environmental policy, in particular in the United Kingdom. The roundtable involved stakeholders such as volunteers, academic, and political environmental governance communities to examine the current environmental policy landscape. This joint knowledge gathering revealed that in many areas, existing paths of collection and use of CS data are well established and operational. However, the growth of the field and the combination of societal and technological changes mean that some of the established roles and organisations need to change, particularly with respect to data standardisation and research funding. This was openly discussed by organisations that currently determine data access and use, such as the National Biodiversity Network, the Joint Nature Conservation Committee advising UK government and administrations, and the UK Environment Agency.
The UK's unified cross-disciplinary research and innovation organisation (UKRI) has recognised the need to invest in infrastructure to support CS by establishing a dedicated funding scheme. Outputs of the roundtable include a policy brief synthesising the results of the event for policy makers (DITOs 2019).

The roundtable provided space for discussion between CS practitioners and actors involved in traditional governance processes (Figure 2). This helped to identify blockages and routes to more comprehensive integration of CS data into environmental governance and their explicit labelling as citizen-generated. One main learning from the event is that the links between CS activities and policy-making processes should be seen as ongoing and iterative engagements. For instance, policy makers and civil servants could be involved in CS project design to communicate policy needs for data and knowledge, while findings from projects should inform government action (DITOs 2019).

\section{Citizen science as an object of research policy}

This mode of governance situates CS as an approach within the practice of science. It addresses the regulation of CS as part of policies for advancing research, technology, and innovation. This mode is shaped by actors, such as the DITOs project and the ECSA, which undertake boundary work (Gieryn 1983) to establish CS as a legitimate approach to conducting research. For this purpose, these actors build links between the constituencies that they aim to represent and the stakeholders that they seek to persuade. Here we find the area of explicit policy-engagement activities within the DITOs project. DITOs advocacy work addressing this mode of governance sought mainly to engage with policy makers in a traditional sense. These included members of public administrations who are responsible for creating and implementing laws and other rules that regulate research, science communication, and science education. The basic argument for this advocacy work was that citizen and DIY science represent recent and rapidly developing phenomena. Therefore, policy 


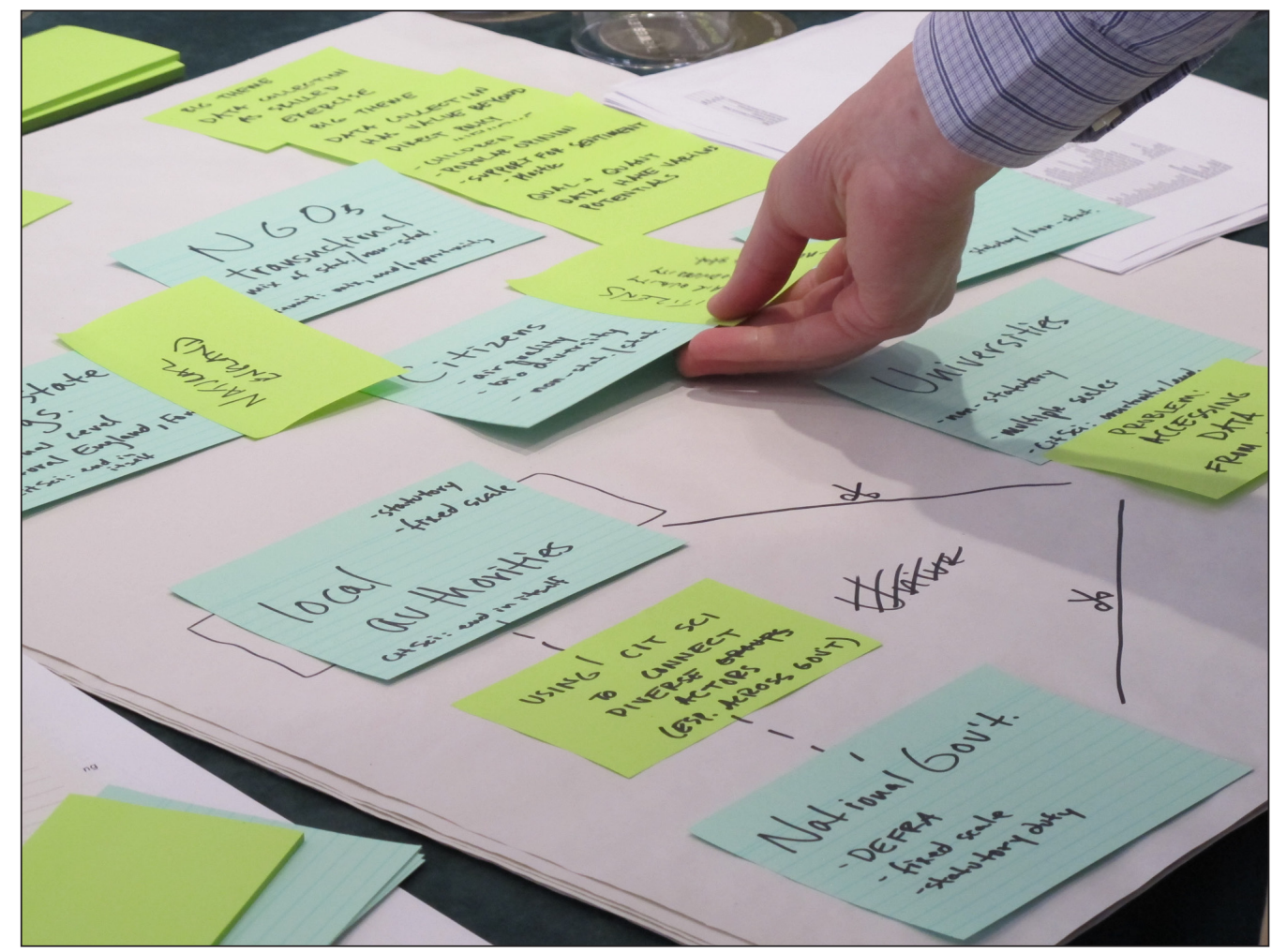

Figure 2: Worksheet at London Stakeholder Roundtable. Photo: Alexandra Berditchevskaia.

makers are likely to lack the requisite knowledge of the characteristics, practical needs, benefits, and challenges of these approaches as well as the contacts to develop them. Through the combination of publications (policy briefs) and face-to-face activities (stakeholder roundtables and discovery trips), the DITOs project provided information and spaces for interaction between policy makers and CS practitioners (Göbel and Agnello 2019). These dedicated activities functioned to introduce policy makers to the practices of CS, outline the relevance of these approaches for their respective contexts and, in the best case, provided resources to support them in affecting change in their institutions. In addition to policy makers, DITOs policy engagement activities also have addressed representatives from other influential organisations in the science and innovation ecosystem, such as funding agencies, academies, foundations, think tanks, or civil society organisations, because they also can play an important role in recognising and establishing CS within the research system (Göbel and Agnello 2019).

This governance mode and the associated advocacy work are founded in a normative understanding of democracy as deliberative and participatory processes involving members of different groups in society. This tradition of political thinking has informed two science policy concepts on which the DITOs project has drawn. The first one is transdisciplinary sustainability research, in which stakeholder engagement is a basis for generating scientific knowledge and implementing practical solutions for issues such as natural resource management conflicts (Pettibone et al. 2018). The second one concerns work on Responsible Innovation that advocates for focussing research on societal problems and for public engagement in early phases of science and technology policy-making (Stilgoe, Owen, and Macnaghten 2013). From the scholarly work associated with these two concepts, DITOs has used the tools of stakeholder roundtables and other formats for direct encounters between researchers and practitioners. The tools have been adapted to the context of advocating for research policy that supports the involvement of people directly into the generation of scientific research (not only into science policy-making and beyond sustainability questions). Similar advocacy work that addresses this mode of governance can be found at national levels. One example is the capacity-building project Citizens create knowledge, knowledge creates citizens (Bonn et al. 2016) funded by the German Federal Ministry of Education and Research. From 2014 to 2016, the project organised a landscape study of existing practices in Germany, several stakeholder roundtables, and the development of a national strategy to advance CS in the country. Building on these results, a pilot funding call for CS projects was created by the ministry in 2016 (BMBF 2016), which sponsored 13 projects with five million Euros (BMBF 2019). DITOs aimed at stimulating similar developments of community building and institutionalisation at the European level.

An illustrative case study of this governance mode within DITOs is the European stakeholder roundtable on CS, DIY science and Responsible Research and Innovation. The event was organised by ECSA and brought together nearly 50 participants for a day of talks and workshops in November 2016 in Berlin. At this event, the DITOs projects created a space for interaction and learning between actors who would not otherwise have had an opportunity to meet face to face: Coordinators of CS projects, representatives of the European Commission, members 
of biohacking spaces, science art gallery managers, representatives of funding agencies, and others. The roundtable involved the sharing of perspectives on CS and the potential role of science policy to enable and support the field. Topics discussed included how CS and DIY science activities are instantiated in biohacking spaces, how pollution sensing collectives in the US establish ties with the federal government, and the role of CS in the EU research agenda for Open Science. Concrete outputs of the roundtable included a report (Göbel et al. 2017) and draft policy briefs that served as further policy engagement instruments (DITOs 2017a; DITOs 2017b). In addition, the event established DITOs as a forum for this type of exchange and further consolidated the role of ECSA as an umbrella organisation and convener at the European level, to facilitate such discussions in the longer term.

The roundtable example also can help to illustrate some of the tensions intrinsic to this governance mode of CS. The first tension concerns processes of institutionalisation and changes that may arise when concepts are adopted by public authorities. At the roundtable, the inputs by European Commission staff testified to the fact that CS already had become included in EU science policy (Göbel et al. 2017). However, this inclusion was predicated on a narrow understanding of CS as crowdsourcing plus education (Vohland and Göbel 2017). Such a limited articulation is at odds with the understanding of CS and DIY science advocated for by DITOs and ECSA, which emphasise the plurality of different approaches and communities of participatory research (Göbel and Agnello 2019). As a result, the focus of the advocacy work was shifted towards emphasizing a diversity of approaches. However, it remains up for debate if this advocacy can be considered successful. Moreover, a second tension regarding representation became visible. The roundtable (and later events) was intended as an opportunity for members of different CS approaches to speak directly to policy makers on their areas of expertise instead of representing them through DITOs or ECSA. Yet several constraints imposed by distinct capacities of "professional" versus "volunteer" CS practitioners challenged this vision in practice. Among many factors, day and time of the week on which to hold such events, the availability of travel cost support, or the possibility of compensating freelance workshop organisers determine whether an event is affordable and truly accessible to representatives from a broad range of CS communities (and other stakeholders). Taking such factors into account and addressing them adequately through dedicated resources is especially important considering the ambition of such roundtables to influence how CS is approached as an object of research policy. For mediating actors such as DITOs and ECSA, working openly and inclusively is thus a necessary condition (Göbel and Agnello 2019).

\section{Citizen science as a policy instrument}

Another way to consider the role of CS in governance is to examine the policy goals that have led to the institutional promotion and funding of CS. This governance mode identifies CS as a policy instrument, which is used by policy makers to advance specific policy goals on relationships between science and society as a form of neoliberal governmentality (Ferguson and Gupta 2002). Because of the many forms and functions that CS activities can have (Eitzel et al. 2017), we can see different agendas that are linked to it. These range from finding cost-effective ways to address environmental regulations (e.g., Vaughan 2014) to the characterisation of the entrepreneurial citizen, who provides ideas and capital (EC 2017) or notions of increasing democracy and improving the societal mission of science (EC 2016, 2017).

The following quote taken from a high-level EU policy document defines a future vision for European research:

"Just as the Internet and globalisation have profoundly changed the way we do business, interact socially, consume culture or buy goods, they are now profoundly impacting how we do research and science ... just as people offer spare rooms via AirBnB, why shouldn't they be allowed to offer spare brain power via citizen science?" (EC 2016: 34, emphasis added).

This quote establishes equivalence between CS and the "sharing economy" (Martin 2016) as exemplified by AirBnB. In this way the policy document valorises disruptive business practices without examining their broader impacts. The negative impact of AirBnB on city centres and liveability has been well documented (Gant 2016; Guttentag 2015). We therefore see here a formation of CS as part of the landscape of disruptive innovations, the marketisation of hitherto unused resources, and the promotion of economic efficiency. This matches the overall sentiment of the policy document about the purpose of investment in research and innovation, with just a short paragraph touching on other dimensions of CS such as addressing societal concerns.

The funding of DITOs under the European Union Framework Programme for Research and Innovation, Horizon 2020, provides a clear demonstration of the use of CS as a deliberate policy instrument. The programme follows regulations that were approved through the European Parliament and the European Council (Regulation [EU] No 1291/2013). Following this regulation, the European Commission issued a detailed work programme with calls that address policy objectives. While those who respond to the call have the freedom to offer different solutions that will address the challenges in the call, the judging process is designed to ensure that the projects will align with the policy objectives for which they are set. The area in which the DITOs project was funded, which is called "Science with and for Society," was explicitly intended to "be instrumental in ... building capacities and developing innovative ways of connecting science to society ... make science more attractive (notably to young people), raise the appetite of society for innovation ..." (EU 2015: 4). The DITOs project responded to a call for "Pan-European public outreach: exhibitions and science cafés engaging citizens in science." Here, the most explicit expectations by policy makers are detailed in the desired impacts: 
"In the short term ... increase public awareness of science and of Responsible Research and Innovation. In the medium term, it will build capacity of local science actors and public authorities to engage with citizens on science and innovation, leading to more public engagement activities after the end of the project. Equally, it will directly encourage more citizens, including women, to participate in science. It will encourage user-led and frugal innovation, and mobilise social resources in the knowledge transfer of ideas - from social imagination to practical implementation. In the long term, it will channel to policy makers at different levels external advice and societal inputs regarding appropriate R\&I policies" (EU 2015: 22, emphasis added).

What is noticeable here is that the project is asked to act as an amplifying instrument to enhance the communication of the policy objectives of Responsible Research \& Innovation (RRI) towards the public and policy makers. In effect, this equals communicating that the research funded by the EU is "doing the right thing." It also captures an expectation that it will promote the vision of "the citizen as entrepreneur" who addresses social problems through innovations that they are developing by themselves with limited resources. Importantly, the requirements in the call are not to challenge any hegemonic position of science, only to promote a representation of science that is following the concept of RRI (cf. Stilgoe, Owen, and Macnaghten 2013).

However, when examining the role of CS as a policy instrument, one should note the obvious caveat, which makes this a complex area escaping direct regulation. First and foremost, once projects have been commissioned, they do not simply continue on their trajectory but typically adapt to the changes in the political context. For example, during the DITOs project the emphasis from promoting RRI as a major objective shifted to highlighting the linkage of CS and Open Science (EC 2017). As policy priorities changed, the DITOs project delivery teams reacted to ensure the alignment of policy outputs of the project to the changing political objectives (the topic of the roundtable discussed in the previous section exemplifies that). Secondly, due to the multiple aspects of CS, e.g., contributing to bigger public awareness to science, increasing informal education, and delivering scientific objectives, the ability of political agendas to make a project deliver a specific policy goal is limited and as with many co-production processes, the potential for unplanned outcomes is high.

\section{Citizen science as socio-technical governance}

Our final category highlights the way that CS functions as socio-technical governance without involving political representatives or established policy channels. "Sociotechnical" means here that the governance takes place not via policy actors, such as the public and stakeholder groups, but through the use of technology, such as physical objects and technical protocols (Marres 2012). Examples of this mode are local-scale groups that are selfmanaging environmental resources or designing technol- ogies to deal with real world problems. The key distinction to the other modes is that socio-technical governance has a direct impact on the way that the world is structured without being reliant on any explicit policy support.

The examples from the DITOs project involve two distinct workshops, one at the Medialab Prado in Madrid and the other in London in relation to Heathrow airport. The Madrid workshop Interactivos? 2017 (https://www.medialab-prado.es/actividades/interactivos 17-reimaginandoel-movimiento-en-la-ciudad-ciencia-ciudadana-para-un) involved designers and artists working together in small teams for two weeks to develop innovative prototypes to solve issues around urban mobility. One group developed visual materials that would encourage people to reduce their environmental footprint by buying local food. Another group developed a prototype that would allow people to map the potholes in their city. Yet another one built a bike-based pirate communication system, while a fourth group developed a game for people to experiment with reducing air pollution. The outputs of the workshop were a range of prototypes that were exhibited to the public at the end of the process. Despite trying to tackle major urban issues, the prototypes could all be implemented in Madrid by local people or communities without requiring official sanction or policy involvement.

The London DITOs workshop involved university students and local residents affected by Heathrow Airport in working together to develop new prototypes and exposure metrics that would account for the noise and air pollution of the airport. During the workshop, the students compared classic methods of gathering evidence, such as technical measurements, with experimental and performative tools that asked for the researcher's perceptual descriptions and engagement. The findings from these experiments were shared with local residents who gave their feedback and joined in proposing different ways in which evidence could be gathered. Novel outputs from the workshop included the concept of producing a public map of refuge areas where noise exposure was low, as well as alternative indicators for the wellbeing of local people which are currently not being gathered.

In both of these examples, the CS workshops created practical and creative approaches for tackling the problems of urban mobility and environmental pollution. What is striking was that the activities attempted to solve these problems directly via the outputs of the workshop such as the prototype devices and metrics, rather than generating data or recommendations to be implemented via deliberative policy-making. The workshops foregrounded the technical prototypes themselves as having an important role to play in finding solutions to these problems. In this way, this approach has similarities with participatory design processes in which the public is invited to directly engage in developing material solutions to a variety of problems (Bjögvinsson et al. 2012). The main audience for these prototypes were other members of the public or stakeholder groups. The notion is that the participants have some specific situated expertise that is a valuable contribution towards and improves the outcomes of the design processes. These workshops transformed governance into 
a socio-technical problem of materials, machines, and protocols rather than just knowledge and deliberative inputs. Applying the prototypes more widely would not require any explicit approval from local authorities, scientists, or the government but only the active involvement of members of the public or interest groups.

CS as socio-technical governance often appears around topics of public concern that involve controversial technologies such as environmental monitoring or genetic modification. This way of building public prototypes in relation to societally resonant issues can be seen as a continuation of older public engagement processes that tried to create public discussion platforms around controversial topics such as genetically modified food (cf. Stilgoe, Owen, and Macnaghten 2013). Where socio-technical governance differs is by tackling these problems directly via material prototypes, protocols, and procedures without passing through discursive and deliberative policy channels (Marres 2012). The impact of this approach is twofold. It enacts a materialisation of governance into devices, while also decentralising governance towards a local level where it involves affected members of the public, who can directly implement changes. Yet, this should not suggest that this approach involves only action and no research. On the contrary, the participants in this mode of CS are often more deeply involved in the scientific, technical, and policy literatures than in other forms of CS (cf. Haklay 2013). For example, the creation of an innovative community sensor network for Heathrow airport required a diverse team with advanced software and hardware expertise as well as detailed knowledge of the relevant legislation (Nold 2018). Despite this depth of scientific and policy engagement, this form of CS is largely neglected within the CS literature.

\section{Discussion}

We have described four modes of how CS and governance relate to each other based on empirical observations from the DITOs activities and the wider literature. Taken together, these four governance modes constitute a heuristic of how CS feeds into, is affected by, forms part of, and exercises governance. Next, we clarify these categories regarding their underlying assumptions and interrelations.

The first two modes of information for policy-making and object of research policy are based on defining CS as an approach to scientific research in which the goal is to put science at the service of policy-making (cf. Storksdieck et al. 2016). Both of these modes are based on established roles and framings of how scientific institutions relate to the political sphere that we discussed above - by relying on citizens to contribute data and knowledge for improving policy-making (information for policy-making) and advocacy for increasing the allocation of public resources towards participatory research (object of research policy). While the focus of the first mode is on the data resulting from CS, the second one considers CS as an approach to research, science education, and communication that is to be regulated. In practice, these categories are typically invoked in, and shape, debates on the quality of data generated through CS activities (e.g., Nature 2015) and on risks of unregulated biotechnological experimentation (e.g., Baumgaertner 2018). These differences point to the key components of these modes of governance. The first one is largely focused on data while the second one largely involves discursive policy events where stakeholders and policy makers meet.

The third and fourth modes of CS as policy instrument and socio-technical governance are largely not discussed in the CS literature but are common within social science analysis of scientific and technical practices. The third dimension suggests that CS is actually a political activity in the way it is used to enact political agendas that come from outside of scientific research. This expansion beyond a purely scientific justification for these activities opens up uncomfortable discussions about the degree to which research activities are entangled with political goals, and therefore requires an examination of the values and aims that are embedded in these goals. We have discussed this in terms of the proliferation of neoliberal ideas, such as the entrepreneurial citizen, yet other ways of addressing societal concerns, e.g., commons-based peer production and broader questions of equity, inclusion, and empowerment still need to be approached. The key component of this governance mode is the presence of political agendas that are embedded into funding calls and consequently recapitulated by academics in their applications. The fourth dimension of socio-technical governance is different from the other three in the way that it relocates where governance is done and how it is made. In this mode CS does not rely on representational politics but "does" governance through its own public practices and sociomaterial methods, such as its technologies. The key components of this mode are explicitly stated public problems that are directly addressed by physical prototypes created by participants.

While these four modes of governance are rooted in different theoretical traditions, in practice they may coexist within a single project. Inherently, they are not mutually exclusive - the form of governance of CS as a policy instrument can happen alongside viewing it as a way to produce information for policy-making. In fact, a project can and will oscillate through these different modes as different actors see different aspects in the project and its outcomes. For example, this can mean that a research funder might see CS as a more efficient and cost-effective way of collecting data. At the same time, a practitioner in the field could interpret the same act as a way to open up scientific practice and question it, and to communicate this potential to the participants. Examining the four modes of governance along with their intelligibility as well as clashes can help to reconstruct aspects of the success and tensions around CS. Successes, on the one hand, can be understood as rooted in making intelligible, or creating productive links between, different political agendas that are associated with CS. Here we mean different not only regarding concrete aims, e.g., different views on the role of the public within the national research system, but different in the sense of operating on various levels and through distinct conceptual framings.

An example of such a success would be to secure funding for the DITOs project, as discussed above, by linking the potential of CS to provide data for decision-making 
(mode 1) to the establishment of CS as a legitimate way of doing research (mode 2) as well as to current EU research policy agendas such as RRI and Open Science (mode 3). On the other hand, tensions in the practice of CS can be traced to clashes between different governance modes. Applying such a perspective to a recent discussion about an international definition of CS one might, for instance, note how arguments making reference to different governance modes coexist without aligning. Heigl et al. (2019) argue that defining minimum quality criteria for CS (mode 2) are essential for making CS a more acceptable source of data for decision-making (mode 1) as well as a more legitimate recipient of funding through grants (mode 3). In contrast, the response by Auerbach et al. (2019) can be read as a claim not to delineate the methodological approaches and research designs that shall be considered part of CS (mode 2) based on criteria for showcasing CS projects on online platforms for attracting attention and participants (mode 4). The coexistence of different governance modes as well as their relations require more attention; however, they are usually hidden by the discussion of CS as a uniform concept (cf. Strasser et al. 2019). Such generalizations open up risks, such as CS becoming a neoliberal facade (Mirowski 2018). Therefore, a better understanding of the multiplicity of CS governance modes and interpretations can contribute analytical sharpness to reflections of CS.

Because such nuances become visible only with a wider heuristic of relations between CS and "the political," we invite others to expand on the concepts that we provide. The four modes of governance described here are not an exhaustive typology of all possible modes across CS projects. There are likely to be other modes that we have not explored because they did not feature in DITOs. However, because DITOs had a direct aim of enhancing and empowering CS at an international scale, it made us aware of these modes as major influences that shaped the practices of the partners in the project. We suggest that explorations of other projects using a similar approach to the one that we are offering can reveal further modes that are relevant to CS activities.

\section{Using the Heuristic to Reflect on DITOs Policy Engagement}

In this section, we use our heuristic to reflect back on the advocacy work done in the DITOs project to provide three examples of how a nuanced understanding of CS governance relations can enrich CS practice. It is easiest to draw lessons from activities that are explicitly oriented towards advocacy, which can be found in the modes information for policy-making and object of research policy. This is where the DITOs project showed explicit agency, also denoted by the deliberate use of the term "policy engagement." Expanding our understanding of governance beyond these two modes to jointly create a heuristic with the additional two archetypes helped to show alternative conceptions of how CS can be related to governance, thereby making it possible to articulate them. This was most clearly expressed in the fourth mode of socio-technical governance, which had been largely invisible in our framing of policy engagement at the proposal writing stage (which focussed on modes 1 and 2). In practice, however, this fourth mode constitutes an important dimension in which CS can be a resource for political action. The DITOs workshops that were focused on prototypes for CS activities highlighted how the creation of evidence and scientific knowledge is intrinsically interwoven with the properties and design of technologies. It was difficult for DITOs to integrate this mode because it relies on the co-design of systems and technologies with citizens, while modes one and two are premised on establishing discursive relationships with public authorities. At first this challenged the consortium, but over time such an extended perspective resulted in rich discussions in which consortium partners questioned some of their basic assumptions, developed new ideas, and jointly formulated questions that will inspire future activities.

The heuristic also was helpful in distinguishing between modes one and two, thus allowing us to more accurately communicate the purpose of the project to CS communities. DITOs was first and foremost focussed on providing communication, coordination, and support for CS, thus it was a project about CS rather than a project that directly and primarily practices CS (although a variety of CS activities were linked to and encouraged by DITOs, see for example McKie 2019). This focus had important implications for how to conceptualise the DITOs policy engagement activities. By using the heuristic, it was possible to clarify that activities in DITOs did not produce environmental data that could be channelled to decision makers (information for policy-making). Yet, what DITOs policy engagement was able to do was to advocate for broader and more explicit use of CS data in policy-making, thus working in mode two that treats CS as an object of policy (in this case environmental instead of research policy). In addition, we switched from doing policy engagement ourselves to working with stakeholders from civil society and building capacity for such advocacy work for CS activities across Europe and in a variety of policy fields.

Finally, the systematic approach of discussing various nuances of "the political" made it possible to address the mode of CS as a policy instrument from the view of "inside" a project. Such a perspective is not usually debated or communicated explicitly owing to the risk of losing (present or future) funding by exposing the political activities involved in doing CS projects. We believe, however, that it is necessary and important to discuss the ways in which we as CS practitioners adapt to, work with, or work around the political agendas transported by institutional support for CS. Only in such a way can we maintain the high degree of reflexivity the field has shown from its early days (Storksdieck et al. 2016) and confront new challenges arising as CS practice becomes increasingly established and diverse. The heuristic presented in this paper thus offers a tool for triggering discussions in a productive way within the practitioner community itself, rather than leaving such matters to the purview of critical comments from the outside.

\section{Conclusions}

This paper has described a growing connection between CS and governance that is made within the academic literature yet suggested that the way this relationship has been con- 
ceptualised so far is limited. Using the lens of the DITOs project, it becomes clear that CS is a spectrum of activities that can "do" governance in a multiplicity of ways. On this basis, we have elaborated a heuristic of four modes of governance of CS. We suggest that this heuristic can contribute to give more substance to policy discussions that seldom specify what specific characterisation of "policy" or "governance" might actually be intended as well as recognising governance that is taking place but currently not being seen. By providing a heuristic of different dimensions, we hope that we will reduce misunderstandings and move towards more precision. This more nuanced understanding of governance in relation to $\mathrm{CS}$ also allows practitioners to be more sensitive towards how "the political" is framed in their projects and the political contexts in which they act. Another benefit is that organisers of CS projects can communicate more clearly about the multiplicity of impacts their work generates. In DITOs it allowed us to better characterise and express the purpose of the project and the effects of political agendas on our activities.

The different modes of governance that we identify suggest the need to develop a broader range of evaluation criteria that take into account different modes of governance and policy engagement work. What would it mean to evaluate the mode of socio-technical governance? Would this require a direct ethnographic examination of the transformative impact of specific CS activities, such as prototyping workshops? Perhaps it would focus on the skills and abilities acquired by the participants to transform the world rather than on the absolute number of traditional policy actors engaged. Developing such criteria would require a process of collective reflection between researchers and practitioners of CS. Moreover, reflecting on the key components of each governance mode may allow us to find alternatives by recombining across the modes addressing different actors and topics in order to develop new forms of CS. For example, how might the idea of bringing stakeholders together at a roundtable be rethought by turning the event into a collective physical construction of a prototype at a CS test site? Using participatory design in such a way could raise questions of local specificity - e.g., where should we test a polluted river and what kinds of new participants might want to engage with their local river? - in a very different manner than, say, a meeting in Brussels. While challenging to achieve, inviting traditional policy makers to take part in hands-on activities might also break down communication barriers and make issues of concern more clear for all the participants. In this way, we hope, CS can not only make the governance of data collection as a source for public policy more open for civic participation but also reflect on how different governance modes can change how we do CS.

Given the growing trend of expansion and formalisation of CS in relation to public policy, it can be expected that these findings from the DITOs project are applicable at various geographic levels of governance. We thus suggest the need for more efforts linking practitioner reflections and academic analysis of the multiplicity of governance modes in CS. Only through such deliberate and cooperative efforts will we be able to develop better forms of CS and governance.

\section{Acknowledgements}

We are grateful to DITOs members for their valuable comments and questions, especially Alexandra Albert, Carole Paleco, Nadia Dewhurst-Richman, and Paweł Wyszomirski for discussions in Ljubljana; Gaia Agnello and Katrin Vohland for critical reflections on DITOs policy engagement activities; and Gina Maskell for her support in reviewing the abstract. The project Doing-It-Together Science (DITOs) has received funding from the European Union's Horizon 2020 research and innovation programme under grant agreement No 709443.

\section{Competing Interests}

The authors have no competing interests to declare.

\section{Author Contributions}

Göbel and Berditchevskaia created the idea of this paper and suggested the initial set of categories. All authors gave shape to the framework, case studies, and contributed to the final review and corrections. Nold introduced the fourth governance mode, provided concepts from STS and political sciences, and wrote the fourth case study. Haklay contributed to theoretical discussions, the third case study, and final review. Göbel and Nold wrote the main text and developed the heuristic and logical flow of the argument. Göbel provided concepts from STS and political sciences, wrote the second case study, used the heuristic to reflect on DITOs policy engagement. She also fine-tuned the argument and discussion, drew a table, took care of references, submitted the paper and acted as corresponding author.

\section{References}

Auerbach, J, Barthelmess, E, Cavalier, D, Cooper, C, Fenyk, H, Haklay, M, Hulbert, J, Kyba, C, Larson, L, Lewandowski, E and Shanley, L. 2019. The problem with delineating narrow criteria for citizen science. PNAS, 116(31): 15336-15337. DOI: https://doi. org/10.1073/pnas.1909278116

Baumgaertner, E. 2018. As D.I.Y. Gene Editing Gains Popularity, 'Someone Is Going to Get Hurt'. The New York Times, May 14 [online access at: https://www. nytimes.com/2018/05/14/science/biohackers-geneediting-virus.html last accessed 15.09.2018].

Berditchevskaia, A, Regalado, C and Van Duin, S. 2017. The changing face of expertise and the need for knowledge transfer. JCOM, 16(4): 1-8. DOI: https:// doi.org/10.22323/2.16040303

Bio Innovation Service. 2018. Citizen science for environmental policy: development of an EU-wide inventory and analysis of selected practices. Final report for the European Commission, DG Environment under the contract 070203/2017/768879/ETU/ENV.A.3, in collaboration with Fundacion Ibercivis and The Natural History Museum. Luxembourg: Publications Office of the European Union. DOI: https://doi. org/10.2779/961304

Bjögvinsson, E, Ehn, P and Hillgren, P. 2012. Design Things and Design Thinking: Contemporary Participatory Design Challenges. Design Issues, 28(3): 101-116. DOI: https://doi.org/10.1162/DESI_a_00165 
Bonn, A, Richter, A, Vohland, K, Pettibone, L, Brandt, M, Feldmann, R, Goebel, C, Grefe, C, Hecker, S, Hennen, L, Hofer, H, Kiefer, S, Klotz, S, Kluttig, T, Krause, J, Küsel, K, Liedtke, C, Mahla, A, Neumeier, V, Premke-Kraus, M, Rillig, MC, Röller, O, Schäffler, L, Schmalzbauer, B, Schneidewind, U, Schumann, A, Settele, J, Tochtermann, K, Tockner, K, Vogel, J, Volkmann, W, von Unger, H, Walter, D, Weisskopf, M, Wirth, C, Witt, T, Wolst, D and Ziegler, D. 2016. Green Paper Citizen Science Strategy 2020 for Germany. Berlin: Helmholtz Centre for Environmental Research (UFZ), German Centre for integrative Biodiversity Research (iDiv) Halle-Jena-Leipzig, Leipzig, Museum für Naturkunde Berlin, Leibniz Institute for Evolution and Biodiversity Science (MfN), Berlin-Brandenburg Institute of Advanced Biodiversity Research (BBIB).

Bonney, R, Shirk, JL, Phillips, TB, Wiggins, A, Ballard, HL, Miller-Rushing, AJ and Parrish, JK. 2014. Next Steps for Citizen Science. Science, 343(6178): 1436-1437. DOI: https://doi.org/10.1126/ science.1251554

Börzel, TA and Risse, T. 2010. Governance without a state: Can it work? Regulation \& Governance, 4(2): 113-134. DOI: https://doi.org/10.1111/j.17485991.2010.01076.x

Bundesministerium für Bildung und Forschung. 2016. Richtlinie zur Förderung von bürgerwissenschaftlichen Vorhaben (Citizen Science). Bundesanzeiger vom 01.08.2016.

Bundesministerium für Bildung und Forschung. 2019. Citizen Science. n.d. Available at: https://www. bmbf.de/de/citizen-science-wissenschaft-erreichtdie-mitte-der-gesellschaft-225.html [Last accessed 14 May 2019].

Chapman, C and Hodges, C. 2016. Can Citizen Science Seriously Contribute to Policy Development? A Decision Maker's View. In: Ceccaroni, L and Piera, J (eds.), Analyzing the Role of Citizen Science in Modern Research, 246-261. Hershey, PA, USA: IGI Global. DOI: https://doi.org/10.4018/978-1-52250962-2.ch012

DITOs consortium. 2017a. BioBlitz: Promoting cross border Research and collaborative Practices for Biodiversity Conservation. DITOs Policy Brief 1, n.d. Available at: http://discovery.ucl.ac.uk/id/ eprint/1573359 [Last accessed 14 May 2019].

DITOs consortium. 2017b. Citizen Science and Open Science: Synergies and Future Areas of Work. DITOs Policy Brief 3, n.d. Available at: http://discovery.ucl. ac.uk/id/eprint/10043574 [Last accessed 14 May 2019].

DITOs consortium. 2019. Citizen Science in UK Environmental Policy. DITOs Policy Brief 7, n.d. Available at: http://discovery.ucl.ac.uk/id/eprint/10073026 [Last accessed 14 May 2019].

Eitzel, MV, Cappadonna, JL, Santos-Long, C, Duerr, RE, Virapongse, A, West, SE, Kyba, CC, Bowser, A, Cooper, CB, Sforzi, A, Metcalfe, AN, Harris, ES, Thiel, M, Haklay, M, Ponciano, L, Roche, J,
Ceccaroni, L, Shilling, FM, Dörler, D, Heigl, F, Kiessling, T, Davis, BY and Jian, Q. 2017. Citizen Science Terminology Matters: Exploring Key Terms. Citizen Science: Theory and Practice, 2(1): 1. DOI: https://doi.org/10.5334/cstp.96

Ellis, C, Adams, TE and Bochner, AP. 2011. Autoethnography: an overview. Historical Social Research, 36(4): 273-290. DOI: https://doi.org/10.12759/ hsr.36.2011.4.273-290

European Commission. 2016. Open Innovation, Open Science, Open to the World - a Vision for Europe. Brussels: European Union.

European Commission. 2017. LAB - FAB - APP - Investing in the European future we want. Brussels: European Union. DOI: https://doi.org/10.2777/477357

European Union. 2015. HORIZON 2020 WORK PROGRAMME 2014 - 2015, 17 April 2015. Science with and for Society. Accessible at: http://ec.europa. eu/research/participants/data/ref/h2020/ wp/2014_2015/main/h2020-wp1415-societies_ en.pdf [Last accessed 8 August 2019].

Ferguson, J and Gupta, A. 2002. Spatializing States: Toward an Ethnography of Neoliberal Governmentality. American Ethnologist, 29(4): 981-1002. DOI: https://doi.org/10.1525/ae.2002.29.4.981

Fundacion Ibercivis. 2017. Informe del observatorio de la ciencia ciudadana en Espana, 16 September 2018. Accessible at: https://ciencia-ciudadana.es/ informe-del-observatorio-de-la-ciencia-ciudadana-enespana-2017/ [Last accessed 8 August 2019].

Gabrys, J, Pritchard, H and Barratt, B. 2016. Just good enough data: Figuring data citizenships through air pollution sensing and data stories. Big Data \& Society, 3(2): 1-14. DOI: https://doi. org/10.1177/2053951716679677

Gant, AC. 2016. Holiday Rentals: The New Gentrification Battlefront. Sociological Research Online, 21(3): 1-9. DOI: https://doi.org/10.5153/sro.4071

Gieryn, TF. 1983. Boundary-Work and the Demarcation of Science from Non-Science: Strains and Interests in Professional Ideologies of Scientists. American Sociological Review, 48(6): 781-795. DOI: https://doi. org/10.2307/2095325

Göbel, C and Agnello, G. 2019. Policy Engagement for Citizen Science. Highlights \& learnings from 3 years of DITOs. Zenodo. DOI: http://doi.org/10.5281/ zenodo. 2800100

Göbel, C, Agnello, G, Baïz, I, Berditchevskaia, A, Evers, L, García, D, Pritchard, H, Luna, S, Ramanauskaite, EM, Serrano, F, Boheemen, PV, Völker, T, Wyszomirski, P and Vohland, K. 2017. European Stakeholder Round Table on Citizen and DIY Science and Responsible Research and Innovation. DITOs Report, July 2017. Accessible at: http:// discovery.ucl.ac.uk/id/eprint/1563626 [Last accessed 8 August 2019].

Gobel, C, Martin, VY and Ramirez-Andreotta, M. 2017. Stakeholder Analysis: International Citizen Science Stakeholder Analysis on Data Interoperability Final Report. Washington, DC: Woodrow Wilson International Center for Scholars, n.d. Accessible at: https:// 
www.wilsoncenter.org/publication/internationalcitizen-science-stakeholder-analysis [Last accessed 8 August 2019].

Guttentag, D. 2015. Airbnb: disruptive innovation and the rise of an informal tourism accommodation sector. Current Issues in Tourism, 18(12): 1192-1217. DOI: https://doi.org/10.1080/13683500.2013.827159

Haklay, M. 2013. Citizen Science and Volunteered Geographic Information - overview and typology of participation. In: Sui, DZ, Elwood, S and Goodchild, MF (eds.), Crowdsourcing Geographic Knowledge, 105-122. Berlin: Springer. DOI: https://doi.org/10.1007/97894-007-4587-2_7

Haklay, M. 2015. Citizen Science and Policy: A European Perspective. Washington, DC: Woodrow Wilson International Center for Scholars, n.d. Accessible at: https:// www.wilsoncenter.org/publication/citizen-scienceand-policy-european-perspective [Last accessed 8 August 2019].

Hecker, S, Bonney, R, Haklay, M, Hölker, F, Hofer, H, Goebel, C, Gold, M, Makuch, Z, Ponti, M, Richter, A, Robinson, L, Rubio Iglesias, J, Owen, R, Peltola, T, Sforzi, A, Shirk, J, Vogel, J, Vohland, K, Witt, T and Bonn, A. 2018. Innovation in Citizen Science Perspectives on Science-Policy Advances. Citizen Science: Theory and Practice, 3(1): 4. DOI: https://doi. org/10.5334/cstp.114

Heigl, F, Kieslinger, B, Paul, KT, Uhlik, J and Dörler, D. 2019. Toward an international definition of citizen science. PNAS, 116(17): 8089-8092. DOI: https://doi. org/10.1073/pnas.1903393116

Houllier, F and Merilhou-Goudard, J. 2016. Les sciences participatives en France. État des lieux, boones practiques \& recommendacions. February 2016. Accessible at: http://www.sciences-participatives.com/Rapport [Last accessed 8 August 2019].

Howe, J. 2006. The Rise of Crowdsourcing. Wired Magazine, 6 January [online access at: http://www.wired. com/wired/archive/14.06/crowds_pr.html last accessed 8 August 2019].

Jasanoff, S. 2005. Designs on Nature: Science and Democracy in Europe and the United States. Princeton, N.J.: Princeton University Press. DOI: https://doi. org/10.1515/9781400837311

Latour, B. 2007. Turning Around Politics: A Note on Gerard de Vries' Paper. Social Studies of Science, 37(5): 811-820. DOI: https://doi. org/10.1177/0306312707081222

Law, J and Ruppert, E. 2013. The Social Life of Methods. Journal of Cultural Economy, 6(3): 229-240. DOI: https://doi.org/10.1080/175303 50.2013.812042

Marres, N. 2012. Material Participation: Technology, the Environment and Everyday Publics. Chippenham: Palgrave Macmillan. DOI: https://doi. org/10.1057/9781137029669

Martin, CJ. 2016. The sharing economy: A pathway to sustainability or a nightmarish form of neoliberal capitalism? Ecological Economics, 121: 149-159. DOI: https://doi.org/10.1016/j.ecolecon.2015.1 1.027
McKie, R. 2019. How an army of 'citizen scientists' is helping save our most elusive animals. The Guardian, 28 July [online access at: https://www.theguardian.com/ environment/2019/jul/28/britain-elusive-animalsfall-into-camera-trap-citizen-scientist last accessed 8 August 2019].

Mirowski, P. 2018. The future(s) of open science. Social Studies of Science, 48(2): 171-203. DOI: https://doi. org/10.1177/0306312718772086

National Advisory Council for Environmental Policy and Technology. 2016. Environmental Protection Belongs to the Public. A Vision for Citizen Science at EPA. EPA 219-R-16-00. n.p.: EPA.

Nature. 2015. Rise of the citizen scientist. Nature, 524: 265. August 20 2015. DOI: https://doi. org/10.1038/524265a

Newman, G, Chandler, M, Clyde, M, McGreavy, B, Haklay, M, Ballard, H, Gray, S, Scarpino, R, Hauptfeld, R, Mellor, D and Gallo, J. 2017. Leveraging the power of place in citizen science for effective conservation decision making. Biological Conservation, 208: 55-64. DOI: https://doi. org/10.1016/j.biocon.2016.07.019

Nimmo, R. 2011. Actor-Network Theory and Methodology: Social Research in a More-Than-Human World. Methodological Innovations Online, 6(3): 108-119. DOI: https://doi.org/10.4256/mio.2011.010

Nold, C. 2018. Turning Controversies into Questions of Design: Prototyping Alternative Metrics for Heathrow Airport. In: Marres, N, Guggenheim, M and Wilkie, A (eds.), Inventing the Social, 94-124. Manchester: Mattering Press.

Ottinger, G. 2010. Buckets of Resistance: Standards and the Effectiveness of Citizen Science. Science, Technology, \& Human Values, 35(2): 244-270. DOI: https:// doi.org/10.1177/0162243909337121

Pettibone, L, Blättel-Mink, B, Balázs, B, Di Giulio, A, Göbel, C, Heubach, K, Hummel, D, Lundershausen, J, Lux, A, Potthast, T, Vohland, K and Wyborn, C. 2018. Transdisciplinary Sustainability Research and Citizen Science: Options for Mutual Learning. GAIA - Ecological Perspectives for Science and Society, 27(2): 222-225. DOI: https:// doi.org/10.14512/gaia.27.2.9

Pocock, MJO, Chapman, DS, Sheppard, LJ and Roy, HE. 2014. Choosing and Using Citizen Science: a guide to when and how to use citizen science to monitor biodiversity and the environment. Wallingford: NERC/Centre for Ecology \& Hydrology.

Rey-Mazon, P, Keysar, H, Dosemagen, S, D'Ignazio, C and Blair, D. 2018. Public Lab: Community-Based Approaches to Urban and Environmental Health and Justice. Sci Eng Ethics, 24(3): 971-997. DOI: https:// doi.org/10.1007/s11948-018-0059-8

Schade, S, Manzoni-Brusati, M, Tsinaraki, C, Kotsev, A, Fullerton, K, Sgnaolin, R, Spinelli, F and Mitton, I. 2017. Using new data sources for policymaking. Luxembourg: Publications Office of the European Union. DOI: https://doi.org/10.2760/739266

Schade, S and Tsinaraki, C. 2016. Survey report: data management in Citizen Science projects. Luxembourg: 
Publications Office of the European Union. DOI: https://doi.org/10.2788/539115

Science Communication Unit. 2013. Science for Environment Policy Indepth Report: Environmental Citizen Science. Report produced for the European Commission DG Environment, December 2013. Bristol: University of the West of England.

Shirk, JL, Ballard, HL, Wilderman, CC, Phillips, T, Wiggins, A, Jordan, R, McCallie, E, Minarchek, M, Lewenstein, BV, Krasny, ME and Bonney, R. 2012. Public Participation in Scientific Research: a Framework for Deliberate Design. Ecology and Society, 17(2): 29. DOI: https://doi.org/10.5751/ES-04705170229

Stilgoe, J, Owen, R and Macnaghten, P. 2013. Developing a framework for responsible innovation. Research Policy, 42(9): 1568-1580. DOI: https://doi. org/10.1016/j.respol.2013.05.008

Storksdieck, M, Shirk, JL, Cappadonna, JL, Domroese, M, Göbel, C, Haklay, M, Miller-Rushing, AJ, Roetman, P, Sbrocchi, C and Vohland, K. 2016. Associations for Citizen Science: Regional Knowledge, Global Collaboration. Citizen Science: Theory and Practice, 1(2): 10. DOI: https://doi.org/10.5334/cstp.55

Strasser, BJ, Baudry, J, Mahr, D, Sanchez, G and Tancoigne, E. 2019. "Citizen Science"? Rethinking Science and Public Participation. Science and
Technology Studies, 32(2): 52-76. DOI: https://doi. org/10.23987/sts.60425

The Parliamentary Office of Science and Technology (POST). 2014. POSTnote 476 August 2014 Environmental Citizen Science. London, UK: POST.

Vaughan, S. 2014. Converging Opportunities: Environmental compliance and citizen science. Policy Brief January 2014. Winnipeg, Manitoba, Canada: International Institute for Sustainable Development (IISD). DOI: https://doi.org/10.1142/S2345748114500018

Vohland, K and Göbel, C. 2017. Open Science und Citizen Science als symbiotische Beziehung? Eine Gegenüberstellung von Konzepten. TATuP, 26(1-2): 18-24. DOI: https://doi.org/10.14512/tatup.26.12.18

Vohland, K, Ziegler, D, Göbel, C, Pettibone, L, John, R, Rückert-John, J, Teichler, T, Talmon-Gros, L, von Blanckenburg, C, Bach, N and Dienel, H. 2016. Zwischenbericht Konzeptstudie zur Anwendbarkeit von Citizen Science in der Ressortforschung des Umweltbundesamts. Berlin: Institut für Sozialinnovation.

Wiggins, A and Crowston, K. 2011. From Conservation to Crowdsourcing: A Typology of Citizen Science. Proceedings of the 2011 44th Hawaii International Conference on System Sciences, Koloa, HI, on 4-7 January 2011. DOI: https://doi.org/10.1109/ HICSS.2011.207

\footnotetext{
How to cite this article: Göbel, C, Nold, C, Berditchevskaia, A and Haklay, M. 2019. How Does Citizen Science "Do" Governance? Reflections from the DITOs Project. Citizen Science: Theory and Practice, 4(1): 31, pp.1-13. DOI: https://doi.org/10.5334/cstp.204 Submitted: 16 September 2018 Accepted: 15 May 2019 Published: 02 December 2019

Copyright: ( 2019 The Author(s). This is an open-access article distributed under the terms of the Creative Commons Attribution 4.0 International License (CC-BY 4.0), which permits unrestricted use, distribution, and reproduction in any medium, provided the original author and source are credited. See https://creativecommons.org/licenses/by/4.0/.
}

] $\mathrm{u}[\quad$ Citizen Science: Theory and Practice is a peer-reviewed open access journal published by Ubiquity Press. 